\title{
Modified Shrinking Core Model for Removal of Hydrogen Sulfide with $\mathbf{T}_{3} \mathbf{O}_{2}$ Desulfurizer
}

\author{
Enguo Wang \\ Department of physics \\ Lingnan normal university \\ Zhanjiang, China \\ e-mail: 945923482@qq.com
}

\author{
Hanxian Guo \\ Institute of coal chemical engineering \\ Taiyuan university of technology \\ Taiyuan, China \\ e-mail: ghx20055@163.com
}

\begin{abstract}
The reaction between $\mathrm{H}_{2} \mathrm{~S}$ and $\mathrm{ZnO}$ fine particles (T302 desulfurizer) was studied. The experiment results show that at the temperature below $573 \mathrm{~K}$, the reaction has stopped before the complete conversion of $\mathrm{ZnO}$ particle is obtained. In order to explain the phenomenon, the modified shrinking core model is put forward on the basis of the change of the porosity of solid product layer during the reaction in the present work. The modified shrinking core model was applied to describe the experiment results of the $\mathrm{H}_{2} \mathrm{~S}$ removal reaction with $\mathrm{ZnO}$ fine particle. The results calculated by the model equation are in good agreement with the experimental data, and the model parameters such as $k_{s}, D_{e 0}$ and alfa at various temperatures were also obtained. The high diffusion activation energy and the maximum conversion of solid reactant in the $\mathrm{H}_{2} \mathrm{~S}$ removal reaction is also explained according to the modified shrinking core model.
\end{abstract}

Keywords-porosity; gas-solid reactions; hydrogen sulfide; zinc oxide; modified shrinking core model

\section{INTRODUCTION}

Noncatalytic, gas-solid reactions are of considerable industrial importance and are readily found in chemical and metallurgical industries, and a large number of examples of this system have been discussed [1-5]. Several models have been applied to describe the kinetic behavior of these reactions. Among these models, grain model $[1,4]$ or the shrinking core model [2] is often applied in modeling the experimental results of gas-solid noncatalytic reaction taking place in the porous pellet and in the nonporous particle, respectively.

Zinc oxide desulfurizer is usually used for the fine clean-up of natural gas, chemical synthesis gas and fuel gas, so the studies on its desulfurization kinetics have been reported. For example, Harrison[4] studied $\mathrm{H}_{2} \mathrm{~S}$ removal with zinc oxide desulfurizer and investigated methodically the corresponding macrokinetics only at 573-1073K. Guo [5] studied the kinetics of the reaction between $\mathrm{H}_{2} \mathrm{~S}$ and zinc oxide (T305 desulfurizer) in the temperature range of 473$673 \mathrm{~K}$, and observed that the maximum conversion of zinc oxide reacted with hydrogen sulfide (signed as $x_{\max }$ ) was less than $100 \%$, and the maximum conversion increased with the reaction temperature at the reaction temperatures below 573K. A similar phenomenon also appeared in other reaction system. However, the phenomena could not be explained using the above-mentioned models satisfactorily. So it is essential to advance a new model, which will be called as the modified shrinking core model.

\section{The Mathematical Models}

For gas-solid reaction in dense solid reactant particle,

$$
\mathrm{A}(\mathrm{g})+\mathrm{B}(\mathrm{s}) \rightarrow \mathrm{cC}(\mathrm{g})+\mathrm{dD}(\mathrm{s})
$$

The shrinking core model considered that solid reactant is dense or has very small porosity, but solid product layer is porous. The porosity of solid product layer does not change during reaction. This hypothesis is also made in the modified shrinking core model. However, the hypothesis that the porosity of solid product layer will change during the reaction will be adopted in the modified shrinking core model. For the sake of simplification, one of the simplest assumptions, that particle size remains unchanged during the reaction while it is not equal to initial size of solid reactant particle, is assumed. Although this model does not precisely represent the whole mechanism of gas-solid reaction, it is the first to take into account the variation of the porosity of solid product layer during the reaction in the shrinking core model.

The following hypotheses are also made in the modified shrinking core model.

1) The reaction will occur at the interface between the porous solid product layer and the unreacted solid.

2) Gas molecule diffuses from the solid particle surface to reaction interface.

3) Isothermal condition prevails.

For the sake of convenience, following assumptions will also be adopted. 1) The resistance of gas film mass transfer from gas bulk to the solid particle surface can be ignored. 2) Spherical solid particles are only considered. 3) Under the reaction condition, the reaction is first order with respect to gaseous reactant $\mathrm{A}$, and the effect of reversibility on the reaction can be neglected.

For reaction (1) taking place in a spherical nonporous particle, the fundamental equations relating the material balance for gaseous component $\mathrm{A}$ can be expressed as follows. 


$$
r^{2} \frac{\partial C_{A}}{\partial r}=\frac{k_{s} r_{c}^{2}}{D_{e}} C_{A c}, R>r>r_{c}
$$

The bounding conditions are

$C_{A}=C_{\mathrm{A} 0}$ at $r=R$ and

$C_{A}=C_{\mathrm{Ac}}$ at $r=r_{\mathrm{c}}$.

Initial condition is

$r_{\mathrm{c}}=r_{0}$ at $t=0$.

In Eq.(2), $r_{c}, R$ are the size of the moving reaction interface and one of the solid particle surface, respectively, and $r_{0}$ is the initial size of solid particle. $C_{\mathrm{A} 0}, C_{\mathrm{A}}$ and $C_{\mathrm{Ac}}$ are the concentration of gaseous component $\mathrm{A}$ in the bulk phase, one in the porous product layer, and one on the surface of the unreacted core, respectively. $k_{\mathrm{s}}, D_{\mathrm{e}}$ are reaction rate constant and effective diffusivity, respectively.

Integrating Eq.(2), we have

$$
C_{A c}=\frac{C_{A 0}}{1+\frac{k_{s} r_{c}^{2}}{D_{e}}\left(\frac{1}{r_{c}}-\frac{1}{R}\right)} .
$$

Material balance for solid component B can be written as follows. At reaction surface

$$
-\frac{d r_{c}}{d t}=\frac{k_{s}}{\rho} C_{A c}
$$

Its initial condition is the same as one of Eq.(2). Replacing Eq.(4) with Eq.(3) obtains

$$
-\frac{\mathrm{dr}_{c}}{\mathrm{dt}}=\frac{\mathrm{k}_{s}}{\rho} \frac{\mathrm{C}_{A 0}}{1+\frac{\mathrm{k}_{s} \mathrm{r}_{c}^{2}}{\mathrm{D}_{\mathrm{e}}}\left(\frac{1}{\mathrm{r}_{c}}-\frac{1}{\mathrm{R}}\right)} .
$$

Solid reactant conversion $x$ is defined as follows.

$$
x=1-r_{c}^{3} / r_{0}^{3} .
$$

Combining Eqns.(5) and (6) gives

$$
\frac{d x}{d t}=\frac{3 k_{s} C_{A 0}}{\rho r_{0}} \frac{(1-x)^{\frac{2}{3}}}{1+k_{S} r_{0}(1-x)^{\frac{2}{3}} / D_{e}\left((1-x)^{-\frac{1}{3}}-\frac{r_{0}}{R}\right)} .
$$

According to literature[4], the effective diffusivity of the gaseous reactant $\mathrm{A}$ in solid product layer can be written as

$$
D_{e}=D_{e 0} \varepsilon
$$

${ }^{2}$ In Eq.(8), $\varepsilon$ is porosity, and can be represented as follows.

$$
\varepsilon=\frac{\alpha-x}{\alpha+x /(Z-1)}
$$

In Eq.(9), $Z$ is the volume of solid product per volume solid reactant. $\alpha$ is the ratio of the increase amount of particle volume during the reaction to its theoretical increase amount, and is defined as follows.

$$
\alpha=\frac{R^{3} / r_{0}^{3}-1}{Z-1}
$$

When $Z<1$, porous solid product forms and $\alpha=1$, so the modified shrinking core model can be reduced to the shrinking core model.

Replacing Eq.(7) with Eqns.(8)-(10) yields

$$
\frac{d x}{d t^{*}}=\frac{3(1-x)^{\frac{2}{3}}}{1+6 \phi^{2}(1-x)^{\frac{2}{3}}\left(\frac{\alpha+x /(Z-1)}{\alpha-x}\right)^{2}\left((1-x)^{-\frac{1}{3}}-[1+\alpha(Z-1)]^{-\frac{1}{3}}\right)}
$$

In Eq.(11), $t^{*}=\frac{k_{s} C_{A 0}}{\rho r_{0}} t$, dimensionless reaction time , and $\phi^{2}=\frac{k_{s} r_{0}}{6 D_{e 0}}$, Thiele module number. Its initial condition is $x=0$ at $t^{*}=0$.

It can be found from Eq.(11) that for the reaction with $Z>1$ and $\alpha<1$, the reaction rate was nearly zero when $x$ approaches $\alpha$, which implies that it is possible for the solid reactant to be consumed incompletely after the reaction, and the maximum conversion of solid reactant is equal to $\alpha$ when $Z>1$ and $\alpha<1$.

When $\alpha \neq 0$, there are no analytic solutions for Eq.(11), so numerical solution should be adopted. In solving this equation, Runge-Kutta method is applied, so that the reaction behavior can be analyzed.

\section{Kineitic Modeling of $\mathrm{H}_{2} \mathrm{~S}$ Removal with ZnO}

T302 type $\mathrm{ZnO}$ desulfurizer with $\rho=4.598 * 10^{-2} \mathrm{~mol} / \mathrm{cm}^{3}$, $r_{0}=2.61 * 10^{-6} \mathrm{~cm}$ was procured from Nanjing Chemical Engineering Company. The physical properties of the sample and the experimental process have been described elsewhere[5]. The experiments were carried out using a thermogravimetric analysis apparatus with flow rate of 700 $\mathrm{ml} / \mathrm{min}$ where the resistance of gas film mass transfer could be ignored. The temperature was varied from approximately $473 \mathrm{~K}$ to $623 \mathrm{~K}$ with the $\mathrm{H}_{2} \mathrm{~S}$ concentration of $0.55 \mathrm{~mol} \%$ in the mixture gases of $\mathrm{N}_{2}, \mathrm{H}_{2} \mathrm{~S}$ and $\mathrm{H}_{2}$. The thermogravimeter 
produced a continuous record of the weight of the solid during the reaction. The change in the weight was converted directly to $\mathrm{ZnO}$ conversion, and the conversion-time data were obtained. Figure 1 gives the experimental conversiontime data obtained using thermogravimeter at various reaction temperatures. It can be seen from these data in Figure 1 that the increase in reaction temperature leads to an increase in reaction rate.

It should be pointed out that the $\mathrm{H}_{2} \mathrm{~S}$ concentration could also affect the conversion-time data for the $\mathrm{H}_{2} \mathrm{~S}$ removal reaction. The reaction is first order with respect to the concentration of $\mathrm{H}_{2} \mathrm{~S}$, which has been verified [5].

For the $\mathrm{H}_{2} \mathrm{~S}$ removal reaction with $\mathrm{ZnO}, \mathrm{Z}$ is equal to the ratio of the molar volume of dense $\mathrm{ZnS}$ particle to one of dense $\mathrm{ZnO}$ particle, and is assumed to be 1.60 . On putting the values of $\rho, C_{\mathrm{A} 0}, r_{0}$ and $Z$ in Eq.(11), we obtain

$$
\begin{aligned}
& \frac{d x}{d t}=3 * 4.583 * 10^{4} k_{s} \times \\
& \frac{(1-x)^{\frac{2}{3}}}{1+\frac{2.61 * 10^{-6} k_{s}}{D_{e}}(1-x)^{\frac{2}{3}}\left(\frac{\alpha+x / 0.6}{\alpha-x}\right)^{2}\left((1-x)^{-\frac{1}{3}}-(1+0.6 \alpha)^{-\frac{1}{3}}\right.},
\end{aligned}
$$

Figure 2 shows the $\mathrm{ZnO}$ conversions calculated using the modified shrinking core model as function of the reaction time by the iteration method. The optimised $k_{\mathrm{s}}, D_{\mathrm{e} 0}$ and $\alpha$ in Eq. (12) can be obtained by making the comparison between the experimental data and the one calculated by the model so as to make the correlation coefficient maximum.

TABLE I. Determination of the Model Parameters

\begin{tabular}{ccccc}
\hline $\begin{array}{c}\text { Temp } \\
\mathbf{K}\end{array}$ & $\alpha$ & $\begin{array}{c}10^{6} \boldsymbol{k}_{\mathrm{s}} \\
\mathbf{m o l} / \mathbf{c m}^{2} \cdot \mathbf{m i n}\end{array}$ & $\begin{array}{c}10^{12} \mathbf{D}_{\mathrm{e} 0} \\
\mathbf{m o l} / \mathbf{c m}^{2} \cdot \mathbf{m i n}\end{array}$ & $\mathbf{R}^{\mathbf{a}}$ \\
\hline 473 & 0.48 & 1.3974 & 0.4902 & 0.9971 \\
513 & 0.6 & 2.1834 & 0.9312 & 0.9934 \\
533 & 0.81 & 2.6201 & 2.0352 & 0.9912 \\
573 & 0.99 & 3.4934 & 5.2402 & 0.9963 \\
593 & 1.12 & 4.1485 & 7.5191 & 0.9964 \\
608 & 1.25 & 4.3668 & 12.664 & 0.9960 \\
623 & 1.33 & 5.0218 & 16.804 & 0.9957 \\
\hline
\end{tabular}

a. $R$ is correlation coefficient.

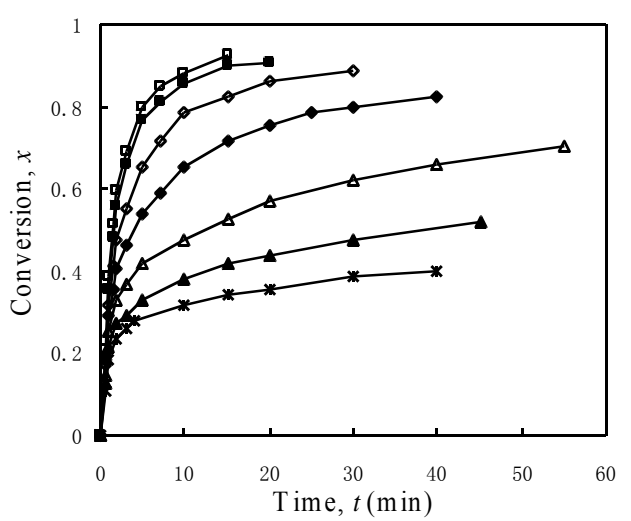

Figure 1. Plot of the conversion of $\mathrm{ZnO}$ versus time at reaction

temperatures of $\square 623 \mathrm{~K}, \square 608 \mathrm{~K}, \diamond 593 \mathrm{~K}, \diamond 573 \mathrm{~K}, \Delta 533 \mathrm{~K}$,

$513 \mathrm{~K}, * 473 \mathrm{~K}$.

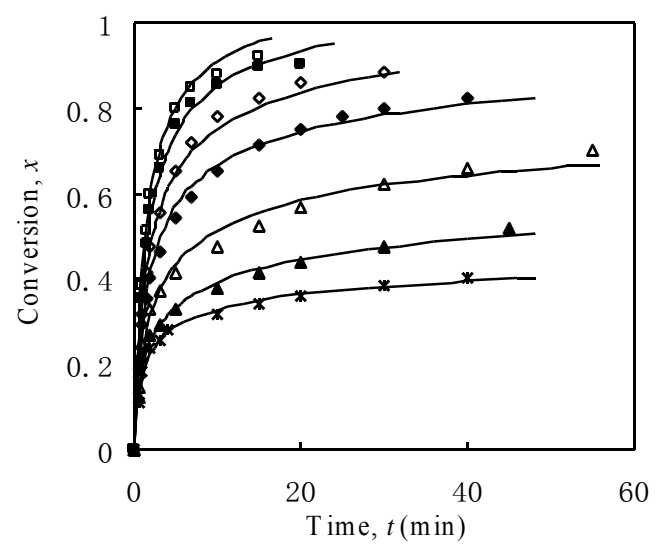

FIGURE 2. Comparison of the predicted value of the $\mathrm{ZnO}$ conversion versus time and the experimental data

It can be seen from Figure 2 that the data calculated using the modified shrinking core model is in good agreement with the experimental ones obtained. So this model makes it possible to predict $\mathrm{ZnO}$ conversion as function of the reaction time.

The activation energy for the chemical reaction and the effective diffusion coefficient of the gaseous reactant can be estimated by an Arrhenius plot, as shown in Figure 3. It can be seen that there is a good linear relationship between $\ln \left(k_{\mathrm{s}}\right)$ as well as $\ln \left(D_{\mathrm{e} 0}\right)$ and the reciprocal of reaction temperature. So Arrhenius relations for the rate constant and the effective diffusion coefficient are given by the following equations.

$$
\begin{aligned}
& k_{\mathrm{s}}=2.551 * 10^{-4} \exp (-20389 / 8.314 T) \\
& D e_{0}=1.527 * 10^{-6} \exp (-59758 / 8.314 T)
\end{aligned}
$$


The activation energy for the chemical reaction was found to be $20.39 \mathrm{~kJ} / \mathrm{mol}$, and the activation energy for diffusion in the $\mathrm{H}_{2} \mathrm{~S}$ removal reaction is averaged to about $59.76 \mathrm{~kJ} / \mathrm{mol}$. Obviously, the diffusion activation energy is

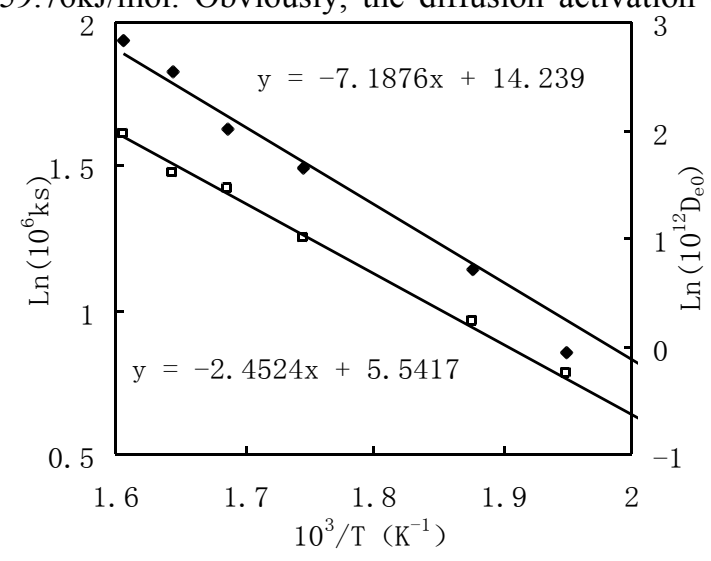

FIGURE 3. Arrhenius plots of calculated rate constant ( $\square$ ) and calculated effective diffusion coefficient $(\bullet)$

very high. For the phenomenon, Guo considered that the diffusion includes both $\mathrm{H}_{2} \mathrm{~S}$ gas diffusion through the porous product layer and $\mathrm{S}^{2-}$ and $\mathrm{O}^{2-}$ ion diffusion in the solid particles [5]. The ion diffusion leads to a high diffusion activation energy. However, according to the modified shrinking core model, the reason for the high diffusion activation energy is that the porosity of solid product layer will change during the reaction, and that the sensitivity of the porosity to temperature is high.

As shown in Table I, the variation of parameter $\alpha$ with the reaction temperature is observed. Plot of $\ln (\alpha)$ vs $1 / T$ is presented in Figure 4. Curve of best fit was obtained for the data of parameter $\alpha$ with consideration of experimental error. The parameter $\alpha$ has a relationship with temperature as

$$
\alpha=36.741 * \exp (-2065.7 / T)
$$

It can be found from Eq. (15) and Figure 4 that the temperature for $\alpha=1$ is $573 \mathrm{~K}$, and that parameter $\alpha$ increases with the reaction temperature. As mentioned above, the maximum conversion of solid reactant during the reaction is equal to $\alpha$ when $\alpha<1$. So when the $\mathrm{H}_{2} \mathrm{~S}$ removal reaction with $\mathrm{ZnO}$ fine particle is carried out at the temperature below the $573 \mathrm{~K}$, the $\mathrm{ZnO}$ particle could be consumed incompletely, and the maximum conversion of $\mathrm{ZnO}$ particle decreases with the reaction temperature. Only at the temperature higher than $573 \mathrm{~K}$, could the complete conversion of $\mathrm{ZnO}$ particle be obtained.

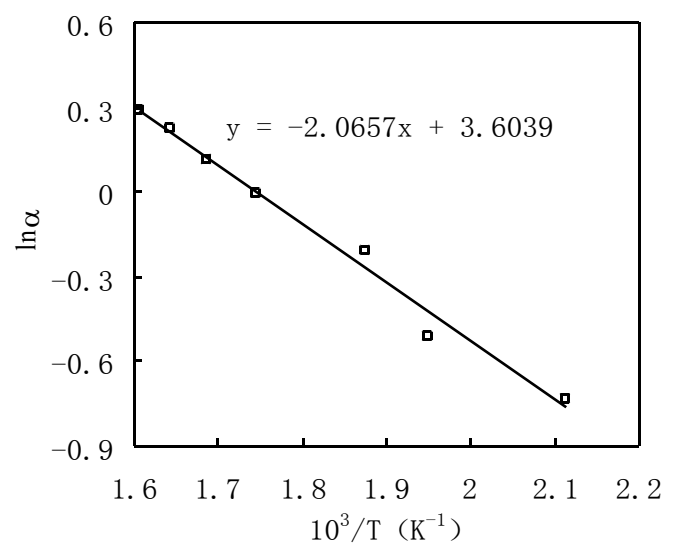

FIGURE 4. Relationship between calculated $\alpha$ value and reaction temperatures

\section{CONCLUSIONS}

The modified shrinking core model is put forward on the basis of the change of the porosity of solid product layer during the reaction, and can be reduced to the shrinking core model when the size of reacted particle is equal to the initial particle size. The modified model is applied to explain the experiment results of the $\mathrm{H}_{2} \mathrm{~S}$ removal reaction with $\mathrm{ZnO}$ in a thermogravimetric analysis apparatus between $473 \mathrm{~K}$ and $623 \mathrm{~K}$. Compared with the shrinking core model, the results calculated by the modified shrinking core model are in good agreement with the experimental data, so the reaction characteristics of $\mathrm{ZnO}$ with $\mathrm{H}_{2} \mathrm{~S}$ can be described by that at the temperature below $573 \mathrm{~K}$, the reaction stopped before the complete conversion of $\mathrm{ZnO}$ particle was obtained. This phenomenon can also be interpreted by the suggested model. Some parameters such as $k_{\mathrm{s}}, \mathrm{D}_{\mathrm{e} 0}$ and $\alpha$ was also obtained.

\section{REFERENCES}

[1] H. Adloo, Z. Safaei, M. N. Esfahany and M. R Ehsani, "Developmen.t of pore network method in simulation of non-catalytic gas-solid reactions-Study of sulfur dioxide chemisorption on copper oxide sorbents," Chem. Eng. J.,2015, pp. 295-312.

[2] P. Sha'ban Nashtaee and B. Khoshandam, "Noncatalytic gas-solid reactions in packed bed reactors: a comparison between numerical and approximate solution techniques," Chem.Eng Commun. Vol. 201, 2014, pp. 120-152, DOI:10.1080/00986445.2013.763229

[3] F. M.YANG F, L. WANG ,S. W. YIN, and Y. H. LI, "Noncatalytic gas-solid reaction model for directly nitridizing silicon powder under atmospheric pressure,” J Univ Sci Technol Beijing,vol.35, Jun. 2013, DOI:10.13374/j.issn1001-053x.2013.06.002

[4] P. V. Ranade and D. P. Harrison, "The variable property grain mode applied to the zinc oxide-hydrogen sulfide reaction," Chem. Eng. Sci. ,vol.36 , 1981, pp. 1079-1089,doi:10.1016/0009-2509(81)80094-2.

[5] S.B.Zhang H.X.Guo and S.Z.Liang, "Microkinetic study of H2S removal by T305 desulfuurizer," J. Taiyuan Univ Technon.vol. 23, Sept. 1991, pp. 1-9. 
International Conference on Materials Chemistry and Environmental Protection (MEEP 2015) 